\title{
Generation of Reactive Oxygen Species by Mitochondria
}

\author{
Pablo Hernansanz-Agustín ${ }^{1, *}$ and José Antonio Enríquez 1,2,* \\ 1 Fundación Centro Nacional de Investigaciones Cardiovasculares Carlos III CNIC, 28029 Madrid, Spain \\ 2 Centro de Investigaciones Biomédica en Red de Fragilidad y Envejecimiento, Saludable-CIBERFES. Av, \\ Monforte de Lemos, 28029 Madrid, Spain \\ * Correspondence: pablo.hernansanz@cnic.es (P.H.-A.); jaenriquez@cnic.es (J.A.E.)
}

check for

updates

Citation: Hernansanz-Agustín, P.; Enríquez, J.A. Generation of Reactive Oxygen Species by Mitochondria. Antioxidants 2021, 10, 415. https:// doi.org/10.3390/antiox10030415

Academic Editor: Petr Ježek

Received: 9 February 2021

Accepted: 1 March 2021

Published: 9 March 2021

Publisher's Note: MDPI stays neutral with regard to jurisdictional claims in published maps and institutional affiliations.

Copyright: (c) 2021 by the authors. Licensee MDPI, Basel, Switzerland. This article is an open access article distributed under the terms and conditions of the Creative Commons Attribution (CC BY) license (https:// creativecommons.org/licenses/by/ $4.0 /)$.

\begin{abstract}
Reactive oxygen species (ROS) are series of chemical products originated from one or several electron reductions of oxygen. ROS are involved in physiology and disease and can also be both cause and consequence of many biological scenarios. Mitochondria are the main source of ROS in the cell and, particularly, the enzymes in the electron transport chain are the major contributors to this phenomenon. Here, we comprehensively review the modes by which ROS are produced by mitochondria at a molecular level of detail, discuss recent advances in the field involving signalling and disease, and the involvement of supercomplexes in these mechanisms. Given the importance of mitochondrial ROS, we also provide a schematic guide aimed to help in deciphering the mechanisms involved in their production in a variety of physiological and pathological settings.
\end{abstract}

Keywords: mitochondria; ROS; mechanism; signalling; disease; supercomplexes

\section{Introduction}

All metazoans require oxygen to survive as it is used by the mitochondria to obtain operational energy. Mitochondria are composed by a double membrane, the inner mitochondrial membrane (IMM) and the outer mitochondrial membrane (OMM), which are separated by the intermembrane space (IMS) and hold the interior of the organelle, the mitochondrial matrix, isolated form the cytoplasm. These organelles use a panoply of carbon sources, from catabolic to anabolic pathways, which generate reducing equivalents useful for the formation of adenosine $5^{\prime}$-triphosphate (ATP). Reducing equivalents, such as nicotinamide adenine dinucleotide hydrogen (NADH) or flavin adenine dinucleotide dihydrogen $\left(\mathrm{FADH}_{2}\right)$, are co-factors in multiple reactions that store electrons derived from metabolic oxidations [1]. NADH flux independently and act as substrate of mitochondrial complex I (CI), which, in turn, reduces ubiquinone to ubiquinol. On the other hand, $\mathrm{FADH}_{2}$ remains linked to the enzymes that are in contact with the IMM, where they interact with $\mathrm{CoQ}$ to recycle their FAD cofactors by reducing ubiquinone to ubiquinol. The most prominent example of FAD-dependent enzymes in mitochondria is complex II (CII). Complex III (CIII) oxidizes ubiquinol to reduce cytochrome c, which, subsequently, donates its electron to complex IV (CIV). Finally, CIV reduces oxygen to water. CI, CIII, and CIV couple the electron flux to the ejection of $\mathrm{H}^{+}$across the IMM, creating a $\mathrm{H}^{+}$electrochemical gradient (negative and alkaline inside), the proton motive force $(\Delta p) . \Delta p$ is used by a fifth complex, the ATP synthase (CV), to transfer $\mathrm{H}^{+}$back to the mitochondrial matrix in an energy-releasing process, which is used to phosphorylate adenosine $5^{\prime}$-diphosphate (ADP) into ATP. As long as the oxygen consumption matches the phosphorylation of ADP, the respiration is coupled to ATP synthesis. Complexes from CI to CIV comprise the mitochondrial electron transport chain (mETC), which, together with CV, form the oxidative phosphorylation system (OXPHOS; Figure 1) [1]. 


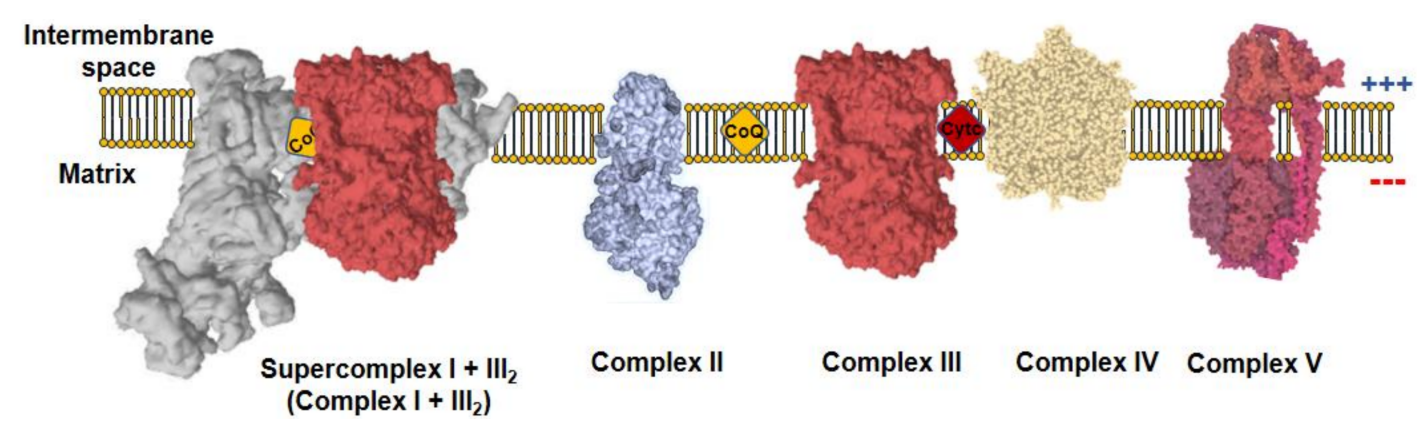

Figure 1. Mitochondrial oxidative phosphorylation system (OXPHOS). The inner mitochondrial membrane (IMM) comprises five protein complexes, which couple the transfer of electrons to $\mathrm{H}^{+}$pumping. Charge distribution across the IMM produces a $\Delta \Psi m$, negative inside. Complex I (CI) is normally found inside supercomplexes with complex III (CIII) (supercomplex $\mathrm{I}+\mathrm{III}_{2}$ ) or $\mathrm{CIII}+$ complex IV (CIV) (N-respirasome), a particularly relevant feature for mitochondrial reactive oxygen species (ROS) production.

$\Delta p$ is actively generated by the OXPHOS system; therefore, it reflects an active process of charge separation across the IMM, unlike the plasma membrane in which the charge separation is carried out by diffusion potential. $\Delta p$ can be further decomposed in mitochondrial membrane potential $(\Delta \Psi m)$ and $\mathrm{pH}$ gradient $(\Delta p H m) . \Delta \Psi m$ is created by the difference in charge distribution across the IMM, being positive in the IMS and negative in the matrix. Similarly, the distribution of $\mathrm{H}^{+}$across the IMM makes the IMS acidic and the matrix alkaline. An often-forgotten integral inner membrane protein that contribute to the $\mathrm{H}^{+}$gradient is the NAD $(\mathrm{P})$ transhydrogenase or NNT. NNT couples hydride transfer of reducing the equivalent between NADH and NADP to proton translocation across the inner mitochondrial membrane at the expenses of $\Delta p$, generating NADPH of the proton gradient, but can work in reverse to generate $\Delta p$ and NADH from NADPH [2]. In addition to its role in ATP synthesis, the $\Delta p$ is utilized by the mitochondria as the driving force to import proteins, metabolites and to balance the ion fluxes across the IMM. Interestingly, the movement of ions and charged molecules across the IMM impacts the $\Delta p$.

One of the more relevant ions that cross the IMM is $\mathrm{Ca}^{2+}$. Mitochondrial $\mathrm{Ca}^{2+}$ uptake is carried out by the inwardly rectifying mitochondrial $\mathrm{Ca}^{2+}$ uniporter (MCU), a highly specific channel for $\mathrm{Ca}^{2+}$ [3]. Thus, the MCU passes $\mathrm{Ca}^{2+}$ down the electrochemical gradient without coupling ATP hydrolysis or transport other ions. Mitochondrion $\mathrm{Ca}^{2+}$ extrusion is primarily carried out by the mitochondrial $\mathrm{Na}^{+} / \mathrm{Ca}^{2+}$ exchanger (NCLX) [4,5] in an electrophoretic process that mediates the extrusion of $3 \mathrm{Na}^{+}$per $1 \mathrm{Ca}^{2+}$. The activity of NCLX depends on the $\mathrm{Na}^{+}$gradient created by the fast acting mitochondrial $\mathrm{Na}^{+} / \mathrm{H}^{+}$exchanger (mNHE), which parallels $\mathrm{Na}^{+}$gradient to $\Delta p H m$ [6]. In this way, $\mathrm{Ca}^{2+}$ and $\mathrm{Na}^{+}$homeostasis becomes engaged to the activity of OXPHOS. Notably, despite the importance of these exchangers for mitochondrial homeostasis, their molecular identities have remained unknown until recently $[5,7,8]$, with the exception of the mNHE whose molecular identification remains to be confirmed.

All organisms are subjected to acute changes in oxygen availability (hyperoxia and hypoxia, respectively) and both result in the production of reactive oxygen species (ROS). ROS are most commonly the product of subsequent one-electron reduction of oxygen. Thus, one electron reduction of oxygen produces superoxide anion $\left(\mathrm{O}_{2}{ }^{--}\right)$, which is the most common first step in all ROS-producing enzymes and a very toxic species. Oneelectron reduction of $\mathrm{O}_{2}{ }^{\bullet-}$ produces hydrogen peroxide $\left(\mathrm{H}_{2} \mathrm{O}_{2}\right)$, which is the best-known ROS acting as second messenger, normally due to its ability of reversibly oxidizing thiols groups on proteins. Subsequent one-electron reduction of $\mathrm{H}_{2} \mathrm{O}_{2}$ yields hydroxyl radical $\left({ }^{\bullet} \mathrm{OH}\right)$, which is an extremely harmful ROS that is notoriously involved in toxic reactions, such as the Fenton reaction. Mitochondrial ROS are involved in numerous physiological processes [9-15] and also link the progression from tissue homeostasis to disease [16-19]. Very surprisingly, the mechanisms of ROS production in live cells and tissues are poorly 
understood. Yet, thanks to the work on isolated mitochondria, we have a progressively deeper knowledge of how these organelles produce ROS [20-24].

\section{Modes of ROS Production by Mitochondria}

Classical experiments with $\mathrm{mETC}$ inhibitors pointed to $\mathrm{CI}$ and $\mathrm{CIII}$ as the major sources of ROS within the mitochondria and the cell. From a general point of view, potential sites of ROS production are triggered depending on the respiration substrate, membrane potential and, if present, the inhibitor used.

Under normal conditions, coupled respiration on glutamate/malate (GM) or pyruvate/malate (PM) activates the Krebs cycle enzymes 2-oxoglutarate dehydrogenase (OGDH), malate dehydrogenase (MDH), and pyruvate dehydrogenase (PDH), and maintains a low membrane potential as $\mathrm{CV}$ is producing $\mathrm{ATP}$. $\mathrm{OGDH}, \mathrm{PDH}$, and $\mathrm{MDH}$ reduce $\mathrm{NAD}^{+}$to $\mathrm{NADH}$, which is, in turn, a substrate of CI. As electrons flow down the mETC they eventually reach CIII and CIV. In this situation, the production of ROS is low, but measurable and is commonly assigned to $\mathrm{CI}$, the outer ubiquinone-binding site of $\mathrm{CIII}\left(\mathrm{CIII}_{\mathrm{o}}\right)$ and OGDH [22-24] in the so-called forward electron transfer (FET) (Figure 2A). This mode of ROS production can be exacerbated by ubiquinone-binding site inhibitors of $\mathrm{CI}$, such as rotenone or piericidin A [25-28], or by inhibitors of the inner ubiquinone-binding site of CIII $\left(\mathrm{CIII}_{\mathrm{i}}\right)$, such as antimicyn A $[29,30]$. On the other hand, to decrease this type of ROS production, especially after the application of the mentioned compounds, inhibitors of the flavin site of CI, such as diphenyleneiodonium (DPI; [31,32]), $\mathrm{CIII}_{\mathrm{o}}$ blockers, such as myxothiazol, stigmatellin, or mucidin [33], and OGDH inhibitors, such as succinyl phosphonate or 3-methyl-2-oxopentanoate [24,34], can be applied.

Succinate is the substrate of the Krebs cycle enzyme succinate dehydrogenase (SDH), also known as CII. SDH is representative of a variety of FAD dependent enzymes in the IMM that reduce ubiquinone, such as glyceraldehyde-3-phosphate dehydrogenase (G3PDH), dihydroorotate dehydrogenase (DHODH), and electron-transferring flavoprotein (ETF) [35]. When reducing potential is provided by CII, or to a lesser extent by other FADdependent enzymes, mitochondria over reduce ubiquinone and, under conditions of mitochondrial hyperpolarization (i.e., inactive CV), electrons are able to flow back through $\mathrm{CI}$, reducing $\mathrm{NAD}^{+}$into $\mathrm{NADH}$ and producing superoxide. This process is known as reverse electron transfer (RET) (Figure 2B). RET is the mode that produces the largest levels of ROS [36] and has been observed in both physiological [12,26] and pathophysiological situations $[16,37,38]$. Notably, the exact site of ROS production by RET is not yet clear as some authors propose that it occurs at the flavin site of $\mathrm{CI}\left(\mathrm{CI}_{\mathrm{N}} ;[36,39,40]\right)$, whereas others suggest the ubiquinone-binding site of $\mathrm{CI}\left(\mathrm{CI}_{\mathrm{Q}}\right)$ plus $\mathrm{CI}_{\mathrm{N}}[41,42]$ or the iron-sulphur cluster N2 [43] as the main actors. The investigations of ROS production by RET have used a variety of commonly used mitochondrial drugs to halt this mechanism: (i) $\mathrm{CI}$ inhibitors such as rotenone, DPI [20,39] or piericidin A [42]; (ii) OXPHOS uncouplers, which are $\triangle \Psi m$-disrupting molecules, such as FCCP $[12,20,22,44]$. As CI inhibitors can impede other modes of ROS production (see below), it is recommended to not only defining RET by its sensitivity to CI blockers (e.g., rotenone sensitivity), but also by using OXPHOS uncouplers. RET can be exacerbated by the incorporation of molecules to increase $\Delta p$ [20], such as the CV inhibitor oligomycin or ATP, and it has been proposed that RET can be modulated by the activity of NNT as regulator of the NADH concentration $[45,46]$. Recently, it has been shown that mice harbouring ND6-P25L mutation in their mitochondrial DNA [47] are unable to produce rotenone-sensitive RET, though they still display some residual FCCP sensitivity [48]. Such inability is due to the capacity of CI to enter into its deactive form in every catalytic cycle, possibly allowing the enzyme to undergo active/deactive (A/D) transition very rapidly under hypoxia [48]. In addition, residual ROS production under succinate oxidation may be caused by the $\mathrm{CIII}_{\mathrm{O}}[23,49]$. 
A Forward electron transport
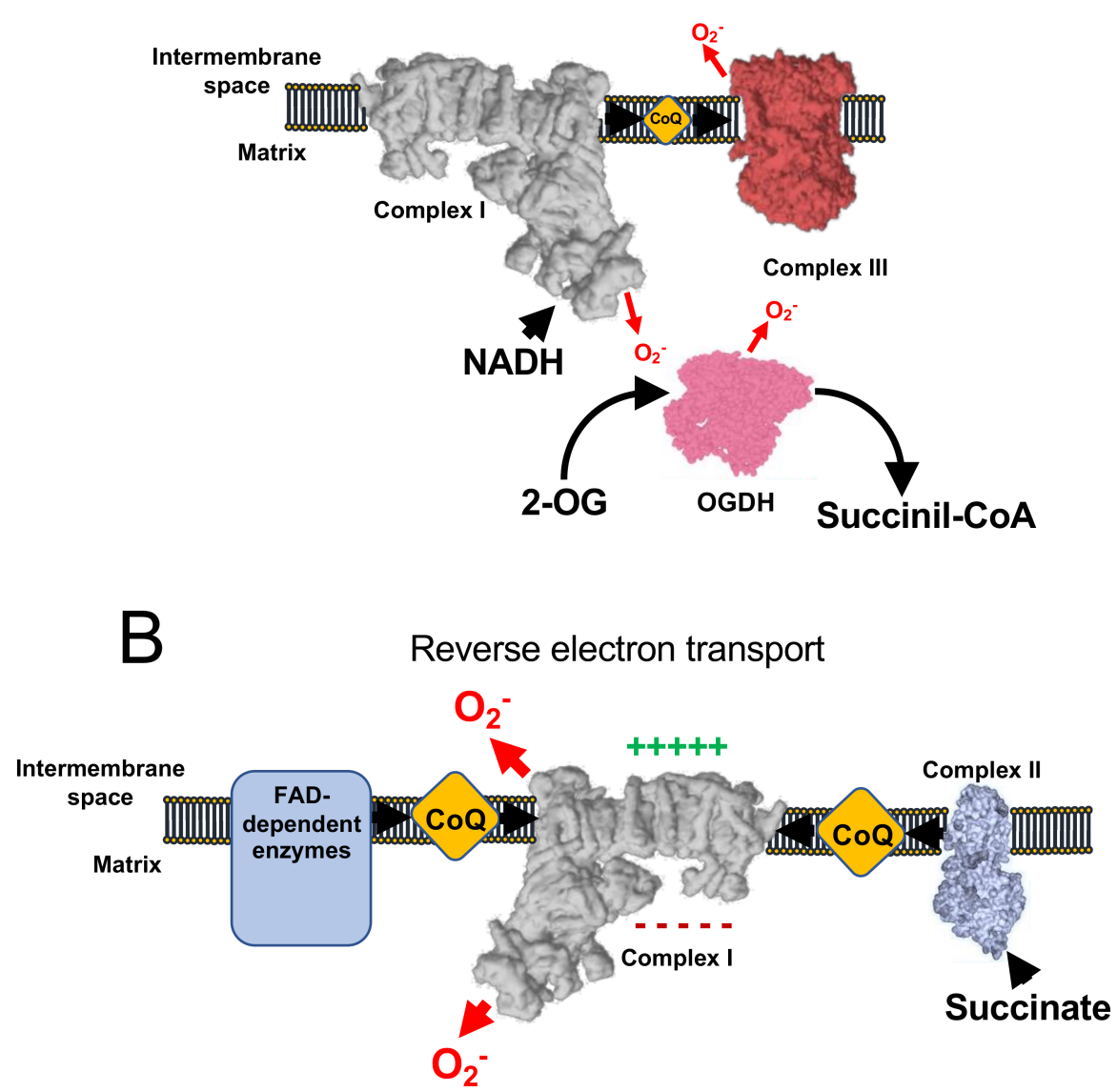

Figure 2. ROS production involving respiratory Complex I. (A) Under normal conditions, minimal amount of mitochondrial ROS are produced, nicotinamide adenine dinucleotide hydrogen (NADH) is oxidized at a high rate, as well as ubiquinol and 2-oxoglutarate. (B) Under conditions of normalto-high $\Delta \Psi m$ and accumulation of reduced CoQ (or succinate) complex I works in the reverse mode, producing high rates of ROS. In addition, a few flavin adenine dinucleotide (FAD)-dependent enzymes have also been shown to contribute to reverse electron transfer (RET).

As commented above, independently of the electron source, $\mathrm{CIII}$ is able to produce ROS upon inhibition with specific molecules. $\mathrm{CIII}_{\mathrm{i}}$ inhibitors, such as Antimycin A promote the accumulation of electrons inside $\mathrm{CIII}$, which reach the $\mathrm{CIII}_{\mathrm{O}}$ site, producing superoxide anion. It is important to note that $\mathrm{CIII}_{\mathrm{o}}$ blockers, such as myxothiazol or stigmatellin do not induce the production of ROS as they render the complex completely oxidized. Indeed, $\mathrm{CIII}_{\mathrm{O}}$ inhibitors block the production of ROS by Antimycin A.

Under specific experimental conditions, when $\mathrm{CI}$ and $\mathrm{CIII}$ are inhibited and the concentration of succinate is low, CII can produce ROS at a significant rate (Figure 3). CII can also operate in forward and reverse modes as it can accept electrons both from succinate (forward) and ubiquinol (reverse). When working in the reverse mode (Figure 3A), CII can produce ROS sensitive to the ubiquinone-binding site inhibitor atpenin $\mathrm{A} 5$, and to the flavin-binding inhibitor malonate. However, when working on the forward mode (Figure 3B), CII can produce ROS that are only sensitive to monate, indicating that the site of ROS production under both modes is the flavin [49]. 


\section{A}

Cll reverse electron transport

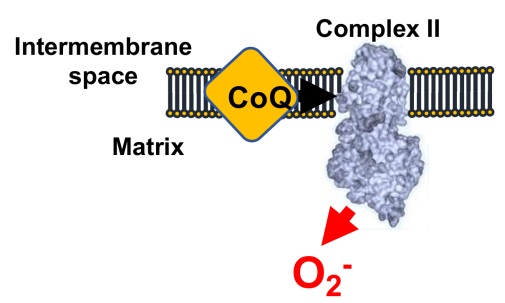

B

\section{Cll forward electron transport}

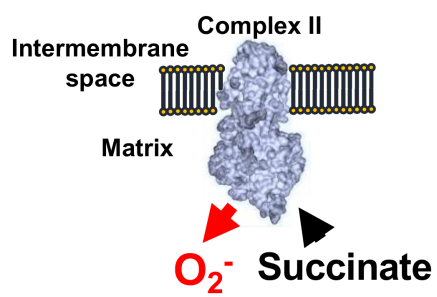

Figure 3. ROS production by Complex II. CII-dependent ROS production has been shown to occur only when CI and CIII are blocked. (A) When CoQ is highly reduced CII generates atpenin A5sensitive ROS in its reverse reaction. (B) The accumulation of succinate promotes malonate-sensitive ROS in its forward reaction.

To note, ROS production triggered by oxidation of G3P can also be promoted by other sources, such as CI (RET) and, more scarcely, CIII $_{\mathrm{O}}[23,49]$. In very specific experimental conditions, in which $\mathrm{CI}$ and $\mathrm{CIII}$ are inhibited, DHODH has been shown to produce ROS through CII and, to a lesser extent, by itself [50]. Moreover, OGDH, branched-chain 2-oxoacid dehydrogenase $(\mathrm{BCODH})$ and pyruvate dehydrogenase $(\mathrm{PDH})$ are potential sources of ROS under precise experimental conditions (Table 1) [34].

Table 1. Summary of the main ROS sources in mitochondria. Respiratory enzymes are able to produce ROS in forward and reverse reactions, as well as under specific physiological conditions, such during acute hypoxia. Biological material is underlined.

\begin{tabular}{|c|c|c|c|c|c|}
\hline Name and Source & System & Substrate(s)/Conditions & Potentiator(s) & Inhibitor(s) & References \\
\hline \multirow[t]{2}{*}{ FET $\left(\mathrm{CI}\right.$ and $\left.\mathrm{CIII}_{\mathrm{o}}\right)$} & $\begin{array}{c}\text { Tissues, cells, and } \\
\text { isolated } \\
\text { mitochondria }\end{array}$ & $\begin{array}{l}\text { Cells and Tissues: } \\
\text { standard culture media } \\
\text { Isolated Mitochondria: } \\
\text { pyruvate, malate and } \\
\text { glutamate }\end{array}$ & $\begin{array}{l}\text { Rotenone, } \\
\text { Piericidin A or } \\
\text { Antimycin A }\end{array}$ & $\begin{array}{l}\text { DPI, myxothiazol, } \\
\text { stigmatellin or } \\
\text { mucidin }\end{array}$ & {$[25,26,28-34]$} \\
\hline & $\begin{array}{l}\text { Cells and isolated } \\
\text { mitochondria }\end{array}$ & Succinate or G3P & $\begin{array}{l}\text { CV inhibitors or } \\
\text { ATP }\end{array}$ & $\begin{array}{c}\text { CI and CII } \\
\text { inhibitors and } \\
\text { OXPHOS } \\
\text { uncouplers (FCCP) }\end{array}$ & $\begin{array}{c}{[13,16,20,22,} \\
36-42,44]\end{array}$ \\
\hline $\mathrm{CIII}_{\mathrm{o}}$ & $\begin{array}{l}\text { Cells and isolated } \\
\text { mitochondria }\end{array}$ & NADH or succinate & Antimycin A & $\begin{array}{l}\text { Myxothiazol or } \\
\text { stigmatellin }\end{array}$ & {$[29,30,51]$} \\
\hline $\begin{array}{r}\text { CII-derived } \\
\text { forward ROS } \\
\text { production }\end{array}$ & $\begin{array}{l}\text { Isolated } \\
\text { mitochondria }\end{array}$ & $\begin{array}{c}\text { Low succinate } \\
\text { concentration, } \mathrm{CI} \text { and } \\
\text { CIII inhibited }\end{array}$ & - & Malonate & [49] \\
\hline $\begin{array}{r}\text { CII-derived } \\
\text { reverse ROS } \\
\text { production }\end{array}$ & $\begin{array}{l}\text { Isolated } \\
\text { mitochondria }\end{array}$ & $\begin{array}{l}\text { Ubiquinol concentration, } \\
\text { CI and CIII inhibited }\end{array}$ & - & $\begin{array}{l}\text { Atpenin A5 and } \\
\text { malonate }\end{array}$ & [49] \\
\hline Hypoxic ROS & $\begin{array}{c}\text { Tissues, cells and } \\
\text { isolated } \\
\text { mitochondria }\end{array}$ & $\begin{array}{l}\text { Cells and Tissues: } \\
\text { normal culture media } \\
\text { Isolated Mitochondria: } \\
\text { Malate, glutamate, } \\
\mathrm{CaCl}_{2} \text { and } \mathrm{NaCl}\end{array}$ & $\begin{array}{c}\text { Monensin, } \\
\text { Nigericin, FCCP } \\
\text { (in normoxic cells) }\end{array}$ & $\begin{array}{c}\text { Rotenone, } \\
\text { piericidin A, } \\
\text { myxothiazol, } \\
\text { malonate, NCLX } \\
\text { inhibitors } \\
\text { (preincubated) }\end{array}$ & [52] \\
\hline
\end{tabular}




\section{ROS in Acute Hypoxia}

Hypoxia is defined as the decreased availability of oxygen in cells and tissues. Low oxygen levels trigger a series of responses that are related to many physiological and pathophysiological scenarios [53]. The counterintuitive observation that hypoxia induced the production of ROS was called the ROS paradox in hypoxia [54,55]. Not surprisingly, these observations were challenged by some authors [56,57]. The discrepancy was solved after measuring the kinetics of ROS production during hypoxia and demonstrating that superoxide production in hypoxia occurs only during the first minutes of hypoxia $[27,30]$. Thus, the discrepancy relayed in the variable timing at which the ROS measurements were taken [57]. Nowadays, though the relationship between chronic adaptation to hypoxia and the production of ROS is still unclear, acute responses to hypoxia is undoubtedly associated to hypoxic ROS generation [52,58-62].

The mechanism of hypoxic ROS production has been solved recently (Figure 4). During the first minutes of hypoxia, CI undergoes the active/deactive (A/D) transition, which consists of a conformational change involving ND3 and other CI subunits. ND3 rearranges to expose its Cys39 [63-66]. A/D transition is a characteristic dormant state of $\mathrm{CI}$ that is not able to perform its enzymatic activity and, therefore, is not able to pump $\mathrm{H}^{+}[27,67]$. As $\mathrm{CI}$ becomes deactive in acute hypoxia, the mitochondrial matrix acidifies and the calcium phosphate precipitates in the matrix partially dissolve, liberating free $\mathrm{Ca}^{2+}$. The rise in matrix $\left[\mathrm{Ca}^{2+}\right]$ activates the mitochondrial $\mathrm{Ca}^{2+} / \mathrm{Na}^{+}$antiporter (NCLX), which promotes the entry of $\mathrm{Na}^{+}$into the mitochondria. $\mathrm{Na}^{+}$accumulates in the matrix and interacts with the carbonyl group in the phospholipids of the inner leaflet of the IMM. The interaction $\mathrm{Na}^{+}$:phospholipid promotes the formation of phospholipid aggregates, which, in turn, diminish the fluidity of IMM. The decrease in IMM fluidity lowers ubiquinol transfer between CII and CIII, while the transfer between CI and CIII is preserved as they are arranged into supercomplexes $[68,69]$. The decrease in ubiquinol transfer between CII and CIII promotes the generation of superoxide at the level of $\mathrm{CIII}_{\mathrm{O}}$ due to the uncoupling of the $\mathrm{Q}$ cycle. This mechanism highlights the role of $\mathrm{Na}^{+}$as second messenger, controlling OXPHOS and hypoxic redox signalling [52].

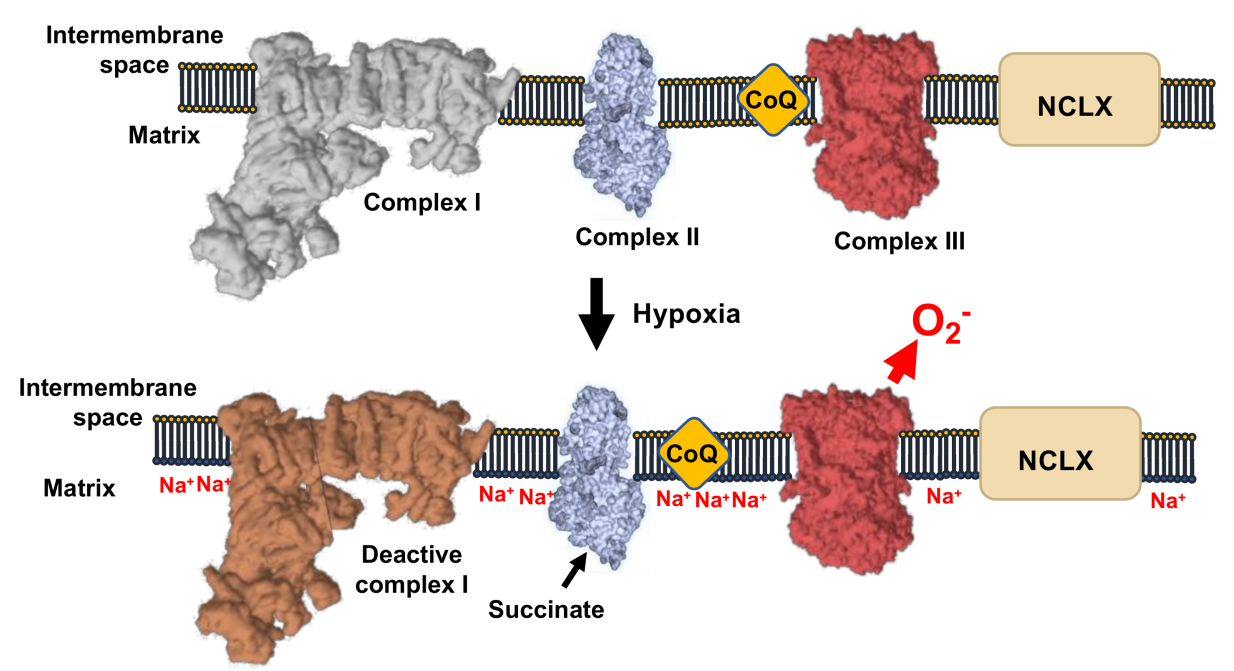

Figure 4. Mechanism of ROS production in hypoxia. CI-deactivation upon oxygen reduction induce de acidification of the mitochondrial matrix, the subsequent solubilization of matrix $\mathrm{Ca}^{2+}$ precipitates. The concomitant elevation of $\mathrm{Ca}^{2+}$ concentration activate the $\mathrm{Ca}^{2+} / \mathrm{Na}^{+}$antiporter (NCLX). This causes the elevation of $\mathrm{Na}^{+}$that decrease the inner membrane fluidity affecting the free CoQ diffusion and increase ROS production by CIII.

Indeed, it has been recently demonstrated that acute inhibition of NCLX ameliorates metabolic changes in failing hearts [70]. This pathway could be inhibited by pharmacological targeting of $\mathrm{CI}$ by rotenone or piericidin A, or by genetic ablation of CI subunits. In 
addition, $\mathrm{CIII}_{\mathrm{o}}$ blockers, such as myxothiazol, $\mathrm{CII}$ inhibitors, such as dimtheylmalonate, and NCLX inhibitors, such as CGP-37157 prevent ROS production in hypoxia. Conversely, this pathway can be triggered in normoxia after application of drugs capable of eliminating the $\triangle p H m$, such as monensin or nigericin. The uncoupler FCCP was unable to inhibit hypoxic ROS at low concentrations. However, concentrations higher than $1 \mu \mathrm{M}$ increased ROS production in normoxia and exposing FCCP pre-treated cells to hypoxia did not to further increase ROS production. This observation indicates that the hypoxic ROS pathway was being activated in normoxia by high concentration of FCCP, which induced acidification of the mitochondrial matrix [27].

As $\mathrm{Na}^{+}$:phospholipid lowers IMM fluidity and ubiquinone transfer between $\mathrm{CII}$ and CIII, it is possible that this interaction also controls RET by CI. In this way, by decreasing IMM fluidity, mitochondrial $\mathrm{Na}^{+}$would lower ubiquinone transfer from $\mathrm{CII}$ to $\mathrm{CI}$, restraining superoxide production. Indeed, data from Elrod's laboratory showed that overexpression of NCLX in mouse heart decreases infarct size and ROS production in ischemia/reperfusion [71], a well-established model of RET in pathophysiology [16]. Thus, increasing mitochondrial $\mathrm{Na}^{+}$would not only increase ROS by CIII , but also decrease ROS by CI-RET. This poises mitochondrial $\mathrm{Na}^{+}$as a modulator of mitochondrial redox signals by selecting the kind of mechanism to be triggered, the location of superoxide production and respiratory complex involved. This may be of particular importance as the downstream adaptative signals triggered by each mechanism could be different, determining the cell fate as shown in flies [38].

It remains to be understood why in isolated mitochondria ROS levels are proportional to the environmental oxygen concentration [72-74]. In the past, this summed up to the arguments against the defenders of the ROS paradox [22]. The fact that the production of ROS does not increase and, rather, decreases with lower oxygen concentration in experiments with isolated mitochondria, whereas it increases in cells and tissues where cellular and molecular integrity are better preserved, provides evidence that key elements are missing or disrupted in experiments with isolated mitochondria. Such discrepancy may be due to several factors. First, it may be that the procedure of extracting mitochondria disrupts the native conformation of the oxygen sensor or the integrity of the oxygen sensing machinery (i.e., calcium phosphate precipitates may partially dissolve in the extraction procedure). Second, it is also possible that the reaction buffers used with isolated mitochondria do not resemble the cytosolic composition. In this respect, routinely used respiration buffers do not contain neither $\mathrm{Na}^{+}$nor $\mathrm{Ca}^{2+}$, which are essential components for hypoxic induced ROS production (e.g., extracellular $\mathrm{Ca}^{2+}$ was shown to be essential in order to increase the magnitude of ROS production), and normally do not use a mixture of substrates (e.g., glutamate, malate plus succinate), which are also involved. Third, as the molecular identity of the oxygen sensor is not known, it is possible that it would be an extramitochondrial component that becomes lost in the mitochondrial isolation procedure.

In summary, though there is still a need to clarify why isolated mitochondria do not increase ROS upon hypoxia, it is now clear that low oxygen levels increase the production of ROS in cells and tissues. In particular, it involves the management of mitochondrial $\mathrm{Na}^{+}$through an unexpected interaction with phospholipids, which is, in turn, potentially implied in all those scenarios in which the hypoxic response, mitochondrial $\mathrm{Ca}^{2+}$ handling, and/or ROS are involved. In this aspect, finding proteins able to control IMM fluidity may be also of great importance as they may become potential targets to lower mitochondrial ROS production and control supercomplex-independent respiration.

\section{The Production of ROS and Supercomplexes}

As mentioned above, electron transfer between $\mathrm{CI}$ and CIII was less sensitive to $\mathrm{Na}^{+}$:phospholipid interaction than electron transfer between CII and CIII. Given that $\mathrm{CI}+\mathrm{CIII}$ activity reflects mostly the activity of supercomplex $\mathrm{I}_{+} \mathrm{III}_{2}$ and that $\mathrm{CII}$ is not superassembled with CIII at significant proportions [1], it becomes clear that supercomplexes are not influenced by $\mathrm{Na}^{+}$signalling [27]. This feature may be important to prevent a 
potentially harmful decrease in respiratory activity at the time a redox signal is delivered. On the other hand, the more plausible molecular mechanism by which this happens would be the existence of a functionally partial segmentation of the CoQ pool $[1,69,75]$.

The assembly of CI, CIII, and CIV in supercomplexes confers novel properties to the electron transport chain. Thus, it allows the partial functional segmentation of the CoQ and cyt c pools [69,75], stabilize CI and regulate its degradation [26,76-78]. Though the role in $\mathrm{CoQ}$ and cyt c functional segmentation was initially questioned [79-82], recent kinetic and structural data have confirmed it [68,83-85].

The existence of differentiated CoQ and cyt $\mathrm{c}$ redox kinetics between superassembled and free complexes explain the concept of functional pools generated by the formation of the supercomplexes. This has immediate consequences on the production of ROS. In a pioneering work, $\mathrm{CI}$ was maintained in supercomplex forming $\mathrm{I}+\mathrm{III}_{2}$ or separated into their individual complexes ( $\mathrm{I}$ and $\mathrm{III}_{2}$ ) with detergents. These experiments were complemented by generation of liposomes reconstituted with purified CI and CIII with variable phospholipid:protein ratio to either maintain them separated or to allow the formation of SC I + $\mathrm{III}_{2}$ [86]. Then, the production of ROS by CI was assessed in both experimental set ups. In either model, the authors found that superassembly of respiratory complexes reduced the production of ROS [86]. This conclusion was corroborated in vivo comparing neurons, where mitochondrial complex I is predominantly assembled into supercomplexes, with astrocytes, that maintain a higher proportion of free complex I. Thus, astrocyte ROS production is several folds higher than that of neurons [87].

The interaction of complexes III and IV to form the N-respirasome $\left(\mathrm{I}+\mathrm{III}_{2}+\mathrm{IV}_{1-2}\right)$ or the Q-respirasome $\left(\mathrm{III}_{2}+\mathrm{IV}_{1-2}\right)$ was also proposed to minimize ROS production from indirect observations in vivo in zebrafish [83] and in a murine model of heteroplasmy [88], indicating that the expression of supercomplex assembly factor 1 (SCAF-1; $[69,83,89]$ ) reduced ROS levels. A direct demonstration of the impact of the tight interaction between complexes III and IV in minimizing ROS production was recently provided by the analysis of partially purified N-respirasomes harbouring or lacking SCAF1 [68]. The presence of SCAF1 determine the tight interaction of CIV and CIII within the N-respirasome, while in its absence CIII and CIV are independently attached to CI [68]. Thus, SCAF1 deficient $\mathrm{N}$-respirasomes were one order of magnitude less efficient in NADH oxidation and in NADH-dependent oxygen consumption, while they generate significantly more ROS [68]. Therefore, superassembly increases the efficiency of respiration while minimizing ROS production.

Having stablished the impact of superassembly in ROS production, several mechanistic questions remain to be answered. For instance, it is yet unclear whether the partial segmentation of the CoQ and cyt c pools is: (1) just a consequence of the proximity of the CI and CIII, and CIII and CIV catalytic sites; (2) or if it is a combination of this proximity and the specific composition of protein and/or phospholipids in the supercomplex microenvironment, which may induce a different partitioning of the substrate carriers between the supercomplex phospholipid environment and that of the IMM. In addition, it remains unexplored whether superassembly impacts on different mechanisms of ROS production, such as RET. Nevertheless, factors influencing superassembly could arise as potential targets for diseases in which ROS are involved.

\section{ROS, Acute Oxygen Sensing, and Calcium Homeostasis}

Sudden exposure to hypoxia promotes organismal adaptative responses, such as hyperventilation or systemic vasodilation which are driven by an arterial chemoreceptor, called carotid body (CB). In particular, the sensory elements in the CB are the glomus cells. Similarly, the pulmonary vasoconstriction (PV) represents other acute response to hypoxia. $\mathrm{PV}$ is mediated by pulmonary aortic smooth muscle cells (PASMCs). It has been proposed that a specific CIV subunit, Cox4i2 is essential for oxygen sensing in both cell types [90-92]. This subunit decreases the affinity of CIV for oxygen, rendering more sensitive to variations in environmental oxygen. 
Interestingly, the interpretation regarding the oxygen sensing mechanism differs in both systems. On one hand, PASMCs hypoxic mitochondrial hyperpolarization would be a prerequisite to superoxide release by CIII, which, through the over-reduction of upstream mETC components, promoted ROS production by uncoupling of the Q-cycle at the level of CIII [91-93]. On the other hand, ROS mediated oxygen sensing in glomus cells require CI [59]. Thus, in glomus cells oxygen sensing would be mediated by the accumulation of ubiquinol followed by RET at CI. This accumulation of ubiquinol would be caused by the reduced oxygen affinity of CIV in the presence of Cox4i2 [58,90].

As mitochondrial hyperpolarization has been postulated as a necessary factor for hypoxic ROS production in PASMCs, further experiments with OXPHOS uncouplers, such as FCCP, measuring ROS in hypoxia would definitely corroborate its involvement (Table 1). In this regard, the use of OXPHOS uncouplers would also be a valuable tool to investigate whether RET is indeed the mechanism underlying ROS production in glomus cells (Table 1). Some other considerations may help to progress in the understanding of the precise mechanism of ROS production in acute oxygen sensing by these specialized cell types. CI activity has been shown essential for ROS production and hypoxic pulmonary vasoconstriction (HPV) in PASMCs [24,93]; thus, given that CII can also feed electrons to CIII and both are necessary for HPV [94], it is possible that CI is involved in ROS production by A/D transition. In addition, it was shown that 2, 4-dinitrophenol (DNP), an OXPHOS uncoupler, or FCCP promoted a biphasic response in HPV; whereas lower amounts had from mild(increase)-to-no effects on HPV, higher concentrations inhibited it. The former was attributed to a sustained vasoconstriction during normoxia, which mimicked the effect of HPV [94]. As mentioned above, OXPHOS uncouplers can activate $\mathrm{Na}^{+}$-hypoxia ROS mechanism in normoxia. Thus, it is possible that the mimicking effect of DNP is due to the normoxic activation of this pathway, which, in turn, could not be further activated in hypoxia due to the presence of the uncoupler (see above, discussion on FCCP and hypoxic ROS production). This hypothesis is supported by results showing that the steady-state contraction of HPV could be inhibited by NCLX blockade [52]. The latter may be explained on behalf of the effect of high concentrations of OXPHOS uncouplers, which can result in cell toxicity, loss of function and cell death. However, it remains to be elucidated whether this effect is due to inhibition of RET or to another ROS-unrelated effect.

Of note, a reduced CIV turnover (i.e., CIV in the presence of Cox4i2) would immediately translate into decreased $\mathrm{H}^{+}$pumping by the mETC, which, at the same rate of $\mathrm{CV}$ activity, would lead to mitochondrial depolarization (and not to hyperpolarization, as it has been consistently observed). Therefore, it is possible that either CV turnover decreases, ATP / ADP ratio augments, or there are other factors involved in $\Delta \Psi m$ regulation during acute hypoxia in PASMCs, which have a larger impact on $\Delta p$ than that of Cox4i2-driven CIV brake. However, it has been shown that the ATP / ADP ratio actually decreases during acute hypoxia in PASMCs [95] and that high ADP inhibits hypoxic response in glomus cells [96]. Alternatively, it is possible that such hyperpolarization, given its rapid occurrence, is a consequence of the activation of the fast-acting $\mathrm{mNHE}$ [97], which would immediately transform the $\Delta p H m$ into $\Delta \Psi m$, enabling RET, as long as there was sufficient ubiquinol accumulation. Activation of $\mathrm{mNHE}$, in turn, would drive to mitochondrial matrix acidification, which would promote liberation of free $\mathrm{Ca}^{2+}$, activation of NCLX, mitochondrial $\mathrm{Na}^{+}$overload and ROS production. Whether the latter pathway occurs in specialized cells would depend on the sensitivity to OXPHOS uncouplers to test RET (Table 1), the steady state of the calcium phosphate precipitates, NCLX expression/activity and the presence of other factors (e.g., proteins, phospholipids, etc.) regulating IMM fluidity. Nevertheless, to test whether it occurs and is triggered in PASMCs and/or glomus cells, monensin can be applied during normoxia (Table 1), as it would activate the hypoxic pathway. It is worth to mention that in very specific conditions and as $\mathrm{mNHE}$ is a reversible antiporter, it is possible that it itself exerts the exit and entry pathways of $\mathrm{Na}^{+}$, which would, in turn, depend on the $\mathrm{Na}^{+}$and $\mathrm{H}^{+}$gradients; rendering $\mathrm{Na}^{+}$accumulation in hypoxic mitochondria independent of NCLX. 
Downstream targets of ROS during acute hypoxia include $\mathrm{K}^{+}$channels and $\mathrm{Ca}^{2+}$ channels. Whereas in some cell types, the main source of $\mathrm{Ca}^{2+}$ has been shown to be the extracellular milieu, in others it has been proposed to be the sarcoplasmic reticulum (SR). Such differences in the $\mathrm{Ca}^{2+}$ sources during acute hypoxia probably reflect the dissimilar composition of $\mathrm{Ca}^{2+}$ channels dedicated to the specific functions of each cell type. Thus, from a common source of ROS, which is the METC, several targets can be modified, regardless of whether they are topologically found in the SR or the plasma membrane, which, in turn, highlights the pleiotropy of ROS as second messengers in different cell types.

\section{Mitochondrial ROS Production in (Patho)Physiology}

Mitochondrial ROS and hypoxia have been involved in the onset and progression of many physiological and pathophysiological settings, ranging from adaptation to hypoxia [52,55,58,59,90-92], regulation of autophagy [96,98], immunity [99-102], differentiation $[103,104]$ to cancer [18], cardiovascular diseases [16], or neurodegenerative diseases [17].

The dysregulation of mitochondrial ROS production has been associated with cancer. Thus, regulation of ERK MAPK signalling pathway by CIII-dependent ROS is required for Kras-induced anchorage-independent growth and tumorigenesis [105]. Loss of SdhB subunit of CII triggers an increase in ROS production and activation of hypoxic inducible factor (HIF)-dependent genes, promoting tumorigenesis [106]. In addition, metastatic progression, which is associated with metabolic reprogramming of the cancer cells and poor outcome, is promoted by mitochondrial ROS [107]. Thus, enhancing mitochondrial antioxidant capacity may be a rational cancer therapeutic approach. Indeed, targeting catalase to the mitochondrial matrix of tumour cells suppressed tumour progression and metastasis in invasive breast cancer in mice [108].

Mitochondrial ROS are related to cardiovascular diseases at different levels. CI RETdependent ROS production has been involved in ischemia-reperfusion (I/R) injury [16,37,38]. As there are several features determining superoxide production by RET, this has allowed the determination of strategies to inhibit ROS-derived RET and injury. For instance, a therapeutic approach was attempted by clamping CI in its deactive state, and, thus, uncapable to do RET, with Mito-SNO, a nitrosylating agent capable of modifying Cys39 of ND3 subunit [109]. Similarly, a missense mutant mouse for the mtDNA encoded CI subunit ND6 in mouse to rapidly undergo A/D transition, showing a significant reduction on RET and a concomitant protection against I/R injury [48]. It has been also shown that mice lacking NCLX have increased ROS production during reperfusion and that its overexpression leads to cardio-protection [71]. The molecular pathways leading to injury in mice lacking NCLX are related to increased mitochondrial $\mathrm{Ca}^{2+}$ overload and, probably, to increased superoxide by RET since the main mitochondrial $\mathrm{Ca}^{2+}$ efflux pathway is not present and mitochondrial $\mathrm{Na}^{+}$does not slow down ubiquinone transfer from $\mathrm{CII}$ to $\mathrm{CI}$. In this way, the knowledge of the molecular mechanism governing ROS production in this pathological scenario has led to the opportunity to develop strategies for the treatment of this disease. Heart failure has been associated to increased ROS production by mitochondria as well. However, the molecular mechanism does not only involve the mETC. Increasing mitochondrial $\mathrm{Ca}^{2+}$ levels in failing myocytes promoted higher turnover of dehydrogenases in the Krebs cycle and production of NADH, which, through the action of NNT, is converted to NADPH, a key molecule in the buffer of oxidative stress. Importantly, lowering the levels of mitochondrial $\mathrm{Ca}^{2+}$ lead to decreased NADPH and higher $\mathrm{H}_{2} \mathrm{O}_{2}$ (not superoxide) levels $[110,111]$. These examples also highlight the importance of an accurate and specific detection of mitochondrial ROS and that increases in $\mathrm{H}_{2} \mathrm{O}_{2}$ do not necessarily arise from increases in superoxide, though they are interconnected species.

Mitochondrial ROS have also been associated to neurological disorders. $\mathrm{Ca}^{2+}$ homeostasis is critical for neuronal work and homeostasis. Engagement of plasma membrane L-type $\mathrm{Ca}^{2+}$ channels during normal autonomous pacemaking in substantia nigra dopamin- 
ergic neurons promoted transient mitochondrial ROS production and vulnerability to injury in Parkinson's disease (PD) development. This was accompanied by mild mitochondrial depolarization, which was, in turn, partially reversed by antagonists of mitochondrial uncoupling proteins [17]. Partial depolarization is known to affect NCLX activity [112], posing NCLX as a possible cause of ROS production in PD. Indeed, halt in NCLX activity has been associated with increased mitochondrial $\mathrm{Ca}^{2+}$ content and neuronal cell death in two PD-associated risk protein pathways [113,114]. As hypoxic ROS may be involved in PD progression, it would be expected that HIF- $1 \alpha$ stabilizes during PD. PINK1 knock-out neurons showed increased levels of mitochondrial ROS and HIF- $1 \alpha$ stabilization, which, in turn, led to a glycolytic switch [115]. It is possible that mitochondrial ROS-driven glycolytic switch reprograms neuron metabolism in such a way that the production of energy through glycolysis does not match the high energetic demands of the neuron, thus, facilitating its entry into apoptosis. Interestingly, modulation of $\mathrm{CI}$ has been associated with development of both PD and Alzheimer's disease (AD; [116-118]). Given that CI can undergo activation and deactivation, and both are related to different modes of ROS production, it would be important to ascertain whether the different physiological states of $\mathrm{CI}$ are related to the pathogenesis in neurological disorders.

Mitochondrial diseases are a form of rare diseases very well defined genetically, but very difficult to treat as their symptomatic manifestations varies greatly with the individuals. It was shown that a mice model of mitochondrial disease extended survival and several other parameters upon exposure to chronic hypoxia [74]. The protection was shown to be independent to the HIF pathway and, interestingly, brain hyperoxia and ROS production, were related to brain damage [74].

In all the previous scenarios, the immune system may play a key role and mitochondrial ROS are also crucial for its proper function. Mitochondrial ROS production is activated by the ROS-triggered CII phosphorylation by Fgr tyrosine kinase [119]. This mechanism drives macrophage activation promoting antibacterial defense [120]. The increase in succinate oxidation causes ROS production by CI-RET and favors inflammation [12]. Very interestingly, blocking CII phosphorylation by Fgr tyrosine kinase or overexpression of catalase in macrophage mitochondrial matrix prevent high fat diet-induced inflammation and obesity [9]. These works highlight the importance of metabolic rewiring of mitochondria in macrophages, from ATP-forming to ROS-producing, to promote a pro-inflammatory state.

In all these settings, different mitochondrial ROS mechanisms may play a role. It is worth to mention that the source of ROS and the mechanism implied can affect greatly what molecular pathway becomes activated downstream. In this regard, ROS target proteins differ when CI or CIII was employed as the source of ROS (PMID: 25451644). In this regard, mitochondrial ROS induced by CI-RET, but not other sources, were able to induce an increase in lifespan in flies (PMID: 27076081). Thus, it is possible that antioxidant treatment may not be as effective as expected since it tackles both beneficial and deleterious ROS [121]. Thus, given the relevance of mitochondrial ROS in so many scenarios it is essential to understand the mechanisms by which they are produced, as it would provide valuable tools to study and treat an array of diseases. Surprisingly, however, the ways of ROS production by mitochondria in vivo are poorly understood. To date there are only a few cases in physiology and disease in which the molecular mechanism of mitochondrial ROS production is clear [12,16,52]. In this regard, the importance of succinate accumulation, $\mathrm{Na}^{+}$ homeostasis or supercomplex formation are a few examples of possible factors modulating ROS production by mitochondria in vivo. We propose a simplified workflow, involving a variety of drugs, to evaluate the mechanisms of ROS production, which may be implied in specific experimental settings (Figure 5). 


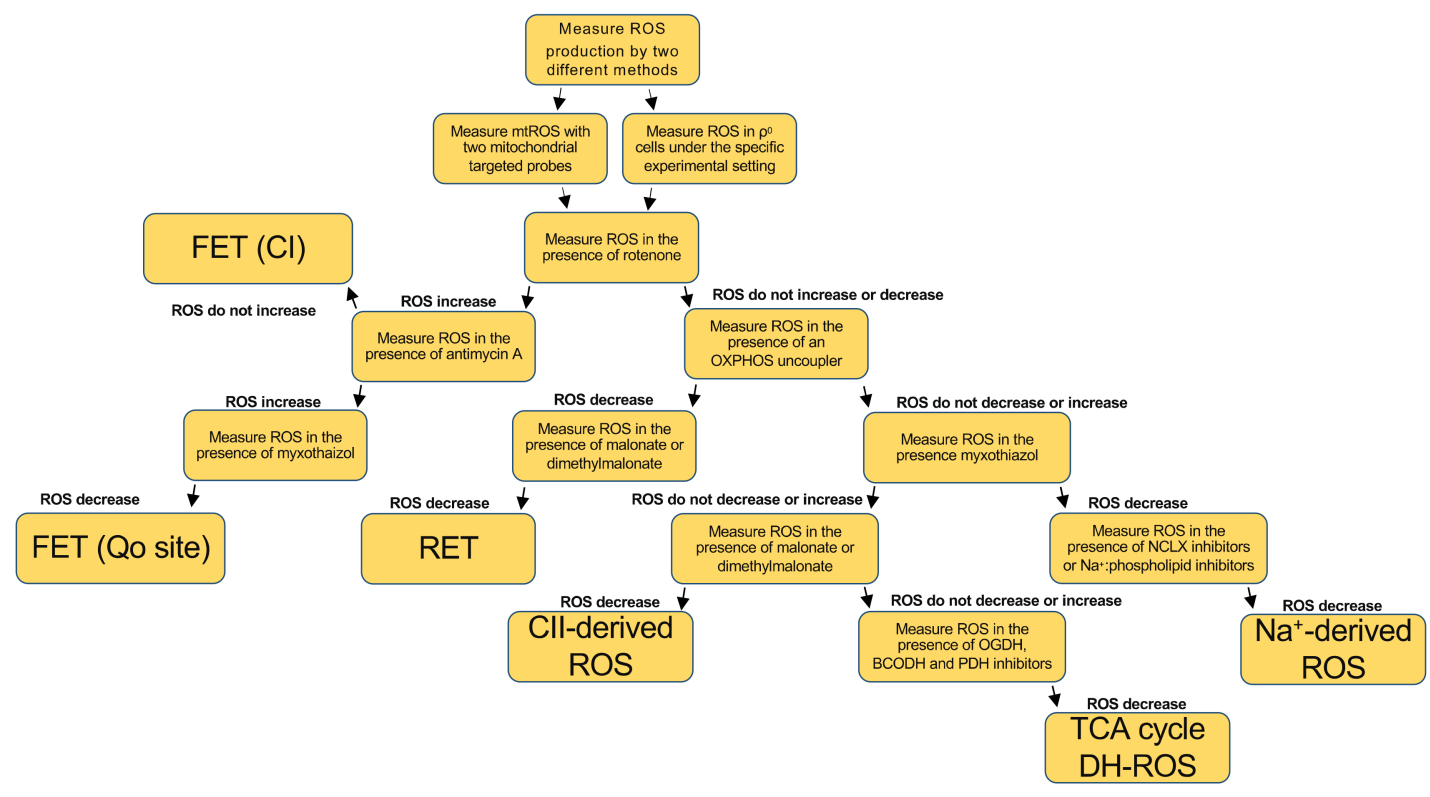

Figure 5. Proposed workflow to evaluate the mechanism of mitochondrial ROS production in cell culture and/or ex vivo. FET (CI) stands for forward electron transfer at the level of CI, FET (Qo site) stands for forward electron transfer at the level of Qo site, RET stands for reverse electron transport, CII-derived ROS stands for ROS production at the level of CII, TCA cycle DH-ROS stands for ROS produced by dehydrogenases at the TCA cycle and $\mathrm{Na}^{+}$-derived ROS stands for ROS produced by $\mathrm{Na}^{+}$:phospholipid interaction.

With the Figure 5 chart we aim to make the study of ROS production by mitochondria easier. It should be noted, however, that this workflow should ideally be accompanied by the corresponding enzymatic activity of the complex involved, in order to discern whether the complex involved in ROS production is a specific target of the experimental setting or compound under study. The advantage of this approach is that it can be used both in isolated mitochondria and cell culture, as well as in tissue culture. Therefore, the investigator can choose whether the structural and functional integrity of mitochondria and cells remains closer to their native environment.

With the tools and hypotheses provided herein, we hope that the study of mitochondrial ROS production, in any (patho)physiological setting, becomes easier for the researchers interested in mitochondrial redox biology.

\section{Concluding Remarks}

Mitochondrial ROS, once considered toxic byproducts of the respiratory activity of the electron transport chain that need to be eliminated at all cost, are today considered critical signalling molecules playing a fundamental role in maintaining health. In addition, the general definition of ROS species is revealingly misleading, since different ROS, like superoxide or hydrogen peroxide, exert their specific functions in different manners. Moreover, the timing and the specific loci where ROS are generated seems to exert very different physiological impact. An explosive advance in the development of this scientific field in the near future is, therefore, expected.

Author Contributions: Conceptualization and writing P.H.-A. and J.A.E. All authors have read and agreed to the published version of the manuscript.

Funding: This study was supported by MINECO: SAF2015-65633-R, RTI2018-099357-B-I00, HFSP (RGP0016/2018) and CIBER (CB16/10/00282). The CNIC is supported by the Instituto de Salud Carlos III (ISCIII), the Ministerio de Ciencia, Innovación y Universidades (MCNU) and the Pro CNIC Foundation and is a Severo Ochoa Center of Excellence (SEV-2015-0505). His research has been financed by Spanish Government grants (ISCIII and AEI agencies, partially funded by the European Union FEDER/ERDF). 
Acknowledgments: The authors thank the whole GENOXPHOS group for suggestions and discussions. Figures created with BioRender.com.

Conflicts of Interest: The authors declare no conflict of interest.

\section{References}

1. Enriquez, J.A. Supramolecular Organization of Respiratory Complexes. Annu. Rev. Physiol. 2016, 78, 533-561. [CrossRef]

2. Kampjut, D.; Sazanov, L.A. Structure and mechanism of mitochondrial proton-translocating transhydrogenase. Nature 2019, 573, 291-295. [CrossRef]

3. Kirichok, Y.; Krapivinsky, G.; Clapham, D.E. The mitochondrial calcium uniporter is a highly selective ion channel. Nature 2004, 427, 360-364. [CrossRef]

4. De Marchi, U.; Santo-Domingo, J.; Castelbou, C.; Sekler, I.; Wiederkehr, A.; Demaurex, N. NCLX protein, but not LETM1, mediates mitochondrial $\mathrm{Ca} 2+$ extrusion, thereby limiting $\mathrm{Ca} 2+$-induced NAD $(\mathrm{P}) \mathrm{H}$ production and modulating matrix redox state. J. Biol. Chem. 2014, 289, 20377-20385. [CrossRef] [PubMed]

5. Palty, R.; Silverman, W.F.; Hershfinkel, M.; Caporale, T.; Sensi, S.L.; Parnis, J.; Nolte, C.; Fishman, D.; Shoshan-Barmatz, V.; Herrmann, S.; et al. NCLX is an essential component of mitochondrial Na+/Ca2+ exchange. Proc. Natl. Acad. Sci. USA 2010, 107, 436-441. [CrossRef]

6. Jung, D.W.; Apel, L.M.; Brierley, G.P. Transmembrane gradients of free Na+ in isolated heart mitochondria estimated using a fluorescent probe. Am. J. Physiol. 1992, 262, C1047-C1055. [CrossRef] [PubMed]

7. Baughman, J.M.; Perocchi, F.; Girgis, H.S.; Plovanich, M.; Belcher-Timme, C.A.; Sancak, Y.; Bao, X.R.; Strittmatter, L.; Goldberger, O.; Bogorad, R.L.; et al. Integrative genomics identifies MCU as an essential component of the mitochondrial calcium uniporter. Nature 2011, 476, 341-345. [CrossRef] [PubMed]

8. De Stefani, D.; Raffaello, A.; Teardo, E.; Szabo, I.; Rizzuto, R. A forty-kilodalton protein of the inner membrane is the mitochondrial calcium uniporter. Nature 2011, 476, 336-340. [CrossRef]

9. Acin-Perez, R.; Iborra, S.; Marti-Mateos, Y.; Cook, E.C.L.; Conde-Garrosa, R.; Petcherski, A.; Munoz, M.D.M.; Martinez de Mena, R.; Krishnan, K.C.; Jimenez, C.; et al. Fgr kinase is required for proinflammatory macrophage activation during diet-induced obesity. Nat. Metab. 2020, 2, 974-988. [CrossRef]

10. Gorlach, A.; Dimova, E.Y.; Petry, A.; Martinez-Ruiz, A.; Hernansanz-Agustin, P.; Rolo, A.P.; Palmeira, C.M.; Kietzmann, T. Reactive oxygen species, nutrition, hypoxia and diseases: Problems solved? Redox Biol. 2015, 6, 372-385. [CrossRef]

11. Latorre-Pellicer, A.; Moreno-Loshuertos, R.; Lechuga-Vieco, A.V.; Sanchez-Cabo, F.; Torroja, C.; Acin-Perez, R.; Calvo, E.; Aix, E.; Gonzalez-Guerra, A.; Logan, A.; et al. Mitochondrial and nuclear DNA matching shapes metabolism and healthy ageing. Nature 2016, 535, 561-565. [CrossRef]

12. Mills, E.L.; Kelly, B.; Logan, A.; Costa, A.S.H.; Varma, M.; Bryant, C.E.; Tourlomousis, P.; Dabritz, J.H.M.; Gottlieb, E.; Latorre, I.; et al. Succinate Dehydrogenase Supports Metabolic Repurposing of Mitochondria to Drive Inflammatory Macrophages. Cell 2016, 167, 457-470.e13. [CrossRef]

13. Mills, E.L.; Pierce, K.A.; Jedrychowski, M.P.; Garrity, R.; Winther, S.; Vidoni, S.; Yoneshiro, T.; Spinelli, J.B.; Lu, G.Z.; Kazak, L.; et al. Accumulation of succinate controls activation of adipose tissue thermogenesis. Nature 2018, 560, 102-106. [CrossRef] [PubMed]

14. Moreno-Loshuertos, R.; Acin-Perez, R.; Fernandez-Silva, P.; Movilla, N.; Perez-Martos, A.; Rodriguez de Cordoba, S.; Gallardo, M.E.; Enriquez, J.A. Differences in reactive oxygen species production explain the phenotypes associated with common mouse mitochondrial DNA variants. Nat. Genet. 2006, 38, 1261-1268. [CrossRef]

15. Vicente-Gutierrez, C.; Bonora, N.; Bobo-Jimenez, V.; Jimenez-Blasco, D.; Lopez-Fabuel, I.; Fernandez, E.; Josephine, C.; Bonvento, G.; Enriquez, J.A.; Almeida, A.; et al. Astrocytic mitochondrial ROS modulate brain metabolism and mouse behaviour. Nat. Metab. 2019, 1, 201-211. [CrossRef]

16. Chouchani, E.T.; Pell, V.R.; James, A.M.; Work, L.M.; Saeb-Parsy, K.; Frezza, C.; Krieg, T.; Murphy, M.P. A Unifying Mechanism for Mitochondrial Superoxide Production during Ischemia-Reperfusion Injury. Cell Metab. 2016, 23, 254-263. [CrossRef]

17. Guzman, J.N.; Sanchez-Padilla, J.; Wokosin, D.; Kondapalli, J.; Ilijic, E.; Schumacker, P.T.; Surmeier, D.J. Oxidant stress evoked by pacemaking in dopaminergic neurons is attenuated by DJ-1. Nature 2010, 468, 696-700. [CrossRef] [PubMed]

18. Harris, I.S.; DeNicola, G.M. The Complex Interplay between Antioxidants and ROS in Cancer. Trends Cell Biol. 2020, 30, 440-451. [CrossRef]

19. Sena, L.A.; Chandel, N.S. Physiological roles of mitochondrial reactive oxygen species. Mol. Cell 2012, 48, 158-167. [CrossRef] [PubMed]

20. Drose, S.; Brandt, U. Molecular mechanisms of superoxide production by the mitochondrial respiratory chain. Adv. Exp. Med. Biol. 2012, 748, 145-169. [CrossRef] [PubMed]

21. Drose, S.; Galkin, A.; Brandt, U. Chapter 26 Measurement of superoxide formation by mitochondrial complex I of Yarrowia lipolytica. Methods Enzymol. 2009, 456, 475-490. [CrossRef]

22. Murphy, M.P. How mitochondria produce reactive oxygen species. Biochem. J. 2009, 417, 1-13. [CrossRef] [PubMed]

23. Quinlan, C.L.; Perevoshchikova, I.V.; Hey-Mogensen, M.; Orr, A.L.; Brand, M.D. Sites of reactive oxygen species generation by mitochondria oxidizing different substrates. Redox Biol. 2013, 1, 304-312. [CrossRef] [PubMed] 
24. Wong, H.S.; Dighe, P.A.; Mezera, V.; Monternier, P.A.; Brand, M.D. Production of superoxide and hydrogen peroxide from specific mitochondrial sites under different bioenergetic conditions. J. Biol. Chem. 2017, 292, 16804-16809. [CrossRef]

25. Chernyak, B.V.; Izyumov, D.S.; Lyamzaev, K.G.; Pashkovskaya, A.A.; Pletjushkina, O.Y.; Antonenko, Y.N.; Sakharov, D.V.; Wirtz, K.W.; Skulachev, V.P. Production of reactive oxygen species in mitochondria of HeLa cells under oxidative stress. Biochim. Biophys. Acta 2006, 1757, 525-534. [CrossRef] [PubMed]

26. Guaras, A.; Perales-Clemente, E.; Calvo, E.; Acin-Perez, R.; Loureiro-Lopez, M.; Pujol, C.; Martinez-Carrascoso, I.; Nunez, E.; Garcia-Marques, F.; Rodriguez-Hernandez, M.A.; et al. The CoQH2/CoQ Ratio Serves as a Sensor of Respiratory Chain Efficiency. Cell Rep. 2016, 15, 197-209. [CrossRef]

27. Hernansanz-Agustin, P.; Ramos, E.; Navarro, E.; Parada, E.; Sanchez-Lopez, N.; Pelaez-Aguado, L.; Cabrera-Garcia, J.D.; Tello, D.; Buendia, I.; Marina, A.; et al. Mitochondrial complex I deactivation is related to superoxide production in acute hypoxia. Redox Biol. 2017, 12, 1040-1051. [CrossRef]

28. Korge, P.; Calmettes, G.; Weiss, J.N. Reactive oxygen species production in cardiac mitochondria after complex I inhibition: Modulation by substrate-dependent regulation of the NADH/NAD(+) ratio. Free Radic. Biol. Med. 2016, 96, 22-33. [CrossRef]

29. Hernansanz-Agustin, P.; Choya-Foces, C.; Martinez-Ruiz, A. Measurement of Superoxide Production in Acute Hypoxia by Fixed-Cell Microscopy. Methods Mol. Biol. 2021, 2202, 43-50. [CrossRef]

30. Hernansanz-Agustin, P.; Izquierdo-Alvarez, A.; Sanchez-Gomez, F.J.; Ramos, E.; Villa-Pina, T.; Lamas, S.; Bogdanova, A.; Martinez-Ruiz, A. Acute hypoxia produces a superoxide burst in cells. Free Radic. Biol. Med. 2014, 71, 146-156. [CrossRef]

31. Gusdon, A.M.; Fernandez-Bueno, G.A.; Wohlgemuth, S.; Fernandez, J.; Chen, J.; Mathews, C.E. Respiration and substrate transport rates as well as reactive oxygen species production distinguish mitochondria from brain and liver. BMC Biochem. 2015, 16, 22. [CrossRef]

32. Liu, Y.; Fiskum, G.; Schubert, D. Generation of reactive oxygen species by the mitochondrial electron transport chain. J. Neurochem. 2002, 80, 780-787. [CrossRef]

33. Fato, R.; Bergamini, C.; Bortolus, M.; Maniero, A.L.; Leoni, S.; Ohnishi, T.; Lenaz, G. Differential effects of mitochondrial Complex I inhibitors on production of reactive oxygen species. Biochim. Biophys. Acta 2009, 1787, 384-392. [CrossRef] [PubMed]

34. Quinlan, C.L.; Goncalves, R.L.; Hey-Mogensen, M.; Yadava, N.; Bunik, V.I.; Brand, M.D. The 2-oxoacid dehydrogenase complexes in mitochondria can produce superoxide/hydrogen peroxide at much higher rates than complex I. J. Biol. Chem. 2014, 289, 8312-8325. [CrossRef] [PubMed]

35. Scialo, F.; Fernandez-Ayala, D.J.; Sanz, A. Role of Mitochondrial Reverse Electron Transport in ROS Signaling: Potential Roles in Health and Disease. Front. Physiol. 2017, 8, 428. [CrossRef] [PubMed]

36. Robb, E.L.; Hall, A.R.; Prime, T.A.; Eaton, S.; Szibor, M.; Viscomi, C.; James, A.M.; Murphy, M.P. Control of mitochondrial superoxide production by reverse electron transport at complex I. J. Biol. Chem. 2018, 293, 9869-9879. [CrossRef]

37. Chouchani, E.T.; Pell, V.R.; Gaude, E.; Aksentijevic, D.; Sundier, S.Y.; Robb, E.L.; Logan, A.; Nadtochiy, S.M.; Ord, E.N.J.; Smith, A.C.; et al. Ischaemic accumulation of succinate controls reperfusion injury through mitochondrial ROS. Nature 2014, 515, 431-435. [CrossRef] [PubMed]

38. Scialo, F.; Sriram, A.; Fernandez-Ayala, D.; Gubina, N.; Lohmus, M.; Nelson, G.; Logan, A.; Cooper, H.M.; Navas, P.; Enriquez, J.A.; et al. Mitochondrial ROS Produced via Reverse Electron Transport Extend Animal Lifespan. Cell Metab. 2016, 23, 725-734. [CrossRef] [PubMed]

39. Pryde, K.R.; Hirst, J. Superoxide is produced by the reduced flavin in mitochondrial complex I: A single, unified mechanism that applies during both forward and reverse electron transfer. J. Biol. Chem. 2011, 286, 18056-18065. [CrossRef]

40. Stepanova, A.; Kahl, A.; Konrad, C.; Ten, V.; Starkov, A.S.; Galkin, A. Reverse electron transfer results in a loss of flavin from mitochondrial complex I: Potential mechanism for brain ischemia reperfusion injury. J. Cereb. Blood Flow Metab. 2017, 37, 3649-3658. [CrossRef]

41. Brand, M.D.; Goncalves, R.L.; Orr, A.L.; Vargas, L.; Gerencser, A.A.; Borch Jensen, M.; Wang, Y.T.; Melov, S.; Turk, C.N.; Matzen, J.T.; et al. Suppressors of Superoxide-H2O2 Production at Site IQ of Mitochondrial Complex I Protect against Stem Cell Hyperplasia and Ischemia-Reperfusion Injury. Cell Metab. 2016, 24, 582-592. [CrossRef]

42. Ohnishi, S.T.; Ohnishi, T.; Muranaka, S.; Fujita, H.; Kimura, H.; Uemura, K.; Yoshida, K.; Utsumi, K. A possible site of superoxide generation in the complex I segment of rat heart mitochondria. J. Bioenerg. Biomembr. 2005, 37, 1-15. [CrossRef]

43. Genova, M.L.; Ventura, B.; Giuliano, G.; Bovina, C.; Formiggini, G.; Parenti Castelli, G.; Lenaz, G. The site of production of superoxide radical in mitochondrial Complex I is not a bound ubisemiquinone but presumably iron-sulfur cluster N2. FEBS Lett. 2001, 505, 364-368. [CrossRef]

44. Komlodi, T.; Geibl, F.F.; Sassani, M.; Ambrus, A.; Tretter, L. Membrane potential and delta pH dependency of reverse electron transport-associated hydrogen peroxide production in brain and heart mitochondria. J. Bioenerg. Biomembr. 2018, 50, 355-365. [CrossRef]

45. Albracht, S.P.; Meijer, A.J.; Rydstrom, J. Mammalian NADH:ubiquinone oxidoreductase (Complex I) and nicotinamide nucleotide transhydrogenase (Nnt) together regulate the mitochondrial production of $\mathrm{H}(2) \mathrm{O}(2)$-implications for their role in disease, especially cancer. J. Bioenerg. Biomembr. 2011, 43, 541-564. [CrossRef] [PubMed]

46. Sharaf, M.S.; Stevens, D.; Kamunde, C. Mitochondrial transition ROS spike (mTRS) results from coordinated activities of complex I and nicotinamide nucleotide transhydrogenase. Biochim. Biophys. Acta Bioenerg. 2017, 1858, 955-965. [CrossRef] 
47. Lin, C.S.; Sharpley, M.S.; Fan, W.; Waymire, K.G.; Sadun, A.A.; Carelli, V.; Ross-Cisneros, F.N.; Baciu, P.; Sung, E.; McManus, M.J.; et al. Mouse mtDNA mutant model of Leber hereditary optic neuropathy. Proc. Natl. Acad. Sci. USA 2012, 109, 20065-20070. [CrossRef] [PubMed]

48. Yin, Z.; Burger, N.; Kula-Alwar, D.; Aksentijevic, D.; Bridges, H.R.; Prag, H.A.; Grba, D.N.; Viscomi, C.; James, A.M.; Mottahedin, A.; et al. Structural basis for a complex I mutation that blocks pathological ROS production. Nat. Commun. 2021, $12,707$. [CrossRef]

49. Quinlan, C.L.; Orr, A.L.; Perevoshchikova, I.V.; Treberg, J.R.; Ackrell, B.A.; Brand, M.D. Mitochondrial complex II can generate reactive oxygen species at high rates in both the forward and reverse reactions. J. Biol. Chem. 2012, 287, 27255-27264. [CrossRef]

50. Hey-Mogensen, M.; Goncalves, R.L.; Orr, A.L.; Brand, M.D. Production of superoxide/H2O2 by dihydroorotate dehydrogenase in rat skeletal muscle mitochondria. Free Radic. Biol. Med. 2014, 72, 149-155. [CrossRef]

51. Drose, S.; Brandt, U. The mechanism of mitochondrial superoxide production by the cytochrome bc1 complex. J. Biol. Chem. 2008, 283, 21649-21654. [CrossRef]

52. Hernansanz-Agustin, P.; Choya-Foces, C.; Carregal-Romero, S.; Ramos, E.; Oliva, T.; Villa-Pina, T.; Moreno, L.; Izquierdo-Alvarez, A.; Cabrera-Garcia, J.D.; Cortes, A.; et al. $\mathrm{Na}(+)$ controls hypoxic signalling by the mitochondrial respiratory chain. Nature 2020, 586, 287-291. [CrossRef] [PubMed]

53. Lopez-Barneo, J.; Simon, M.C. Cellular adaptation to oxygen deficiency beyond the Nobel award. Nat. Commun. 2020, 11, 607. [CrossRef] [PubMed]

54. Chandel, N.S.; Maltepe, E.; Goldwasser, E.; Mathieu, C.E.; Simon, M.C.; Schumacker, P.T. Mitochondrial reactive oxygen species trigger hypoxia-induced transcription. Proc. Natl. Acad. Sci. USA 1998, 95, 11715-11720. [CrossRef] [PubMed]

55. Guzy, R.D.; Hoyos, B.; Robin, E.; Chen, H.; Liu, L.; Mansfield, K.D.; Simon, M.C.; Hammerling, U.; Schumacker, P.T. Mitochondrial complex III is required for hypoxia-induced ROS production and cellular oxygen sensing. Cell Metab. 2005, 1, 401-408. [CrossRef] [PubMed]

56. Archer, S.L.; Huang, J.; Henry, T.; Peterson, D.; Weir, E.K. A redox-based O2 sensor in rat pulmonary vasculature. Circ. Res. 1993, 73, 1100-1112. [CrossRef]

57. Chua, Y.L.; Dufour, E.; Dassa, E.P.; Rustin, P.; Jacobs, H.T.; Taylor, C.T.; Hagen, T. Stabilization of hypoxia-inducible factor1alpha protein in hypoxia occurs independently of mitochondrial reactive oxygen species production. J. Biol. Chem. 2010, 285, 31277-31284. [CrossRef] [PubMed]

58. Arias-Mayenco, I.; Gonzalez-Rodriguez, P.; Torres-Torrelo, H.; Gao, L.; Fernandez-Aguera, M.C.; Bonilla-Henao, V.; Ortega-Saenz, P.; Lopez-Barneo, J. Acute O2 Sensing: Role of Coenzyme QH2/Q Ratio and Mitochondrial ROS Compartmentalization. Cell Metab. 2018, 28, 145-158.e144. [CrossRef] [PubMed]

59. Fernandez-Aguera, M.C.; Gao, L.; Gonzalez-Rodriguez, P.; Pintado, C.O.; Arias-Mayenco, I.; Garcia-Flores, P.; Garcia-Perganeda, A.; Pascual, A.; Ortega-Saenz, P.; Lopez-Barneo, J. Oxygen Sensing by Arterial Chemoreceptors Depends on Mitochondrial Complex I Signaling. Cell Metab. 2015, 22, 825-837. [CrossRef] [PubMed]

60. Paddenberg, R.; Ishaq, B.; Goldenberg, A.; Faulhammer, P.; Rose, F.; Weissmann, N.; Braun-Dullaeus, R.C.; Kummer, W. Essential role of complex II of the respiratory chain in hypoxia-induced ROS generation in the pulmonary vasculature. Am. J. Physiol. Lung Cell. Mol. Physiol. 2003, 284, L710-L719. [CrossRef]

61. Smith, K.A.; Schumacker, P.T. Sensors and signals: The role of reactive oxygen species in hypoxic pulmonary vasoconstriction. J. Physiol. 2019, 597, 1033-1043. [CrossRef] [PubMed]

62. Waypa, G.B.; Smith, K.A.; Schumacker, P.T. O2 sensing, mitochondria and ROS signaling: The fog is lifting. Mol. Aspects Med. 2016, 47-48, 76-89. [CrossRef]

63. Agip, A.A.; Blaza, J.N.; Bridges, H.R.; Viscomi, C.; Rawson, S.; Muench, S.P.; Hirst, J. Cryo-EM structures of complex I from mouse heart mitochondria in two biochemically defined states. Nat. Struct. Mol. Biol. 2018, 25, 548-556. [CrossRef] [PubMed]

64. Blaza, J.N.; Vinothkumar, K.R.; Hirst, J. Structure of the Deactive State of Mammalian Respiratory Complex I. Structure 2018, 26, 312-319.e313. [CrossRef] [PubMed]

65. Galkin, A.; Meyer, B.; Wittig, I.; Karas, M.; Schagger, H.; Vinogradov, A.; Brandt, U. Identification of the mitochondrial ND3 subunit as a structural component involved in the active/deactive enzyme transition of respiratory complex I. J. Biol. Chem. 2008, 283, 20907-20913. [CrossRef]

66. Kampjut, D.; Sazanov, L.A. The coupling mechanism of mammalian respiratory complex I. Science 2020, 370, eabc4209. [CrossRef]

67. Drose, S.; Stepanova, A.; Galkin, A. Ischemic A/D transition of mitochondrial complex I and its role in ROS generation. Biochim. Biophys. Acta 2016, 1857, 946-957. [CrossRef] [PubMed]

68. Calvo, E.; Cogliati, S.; Hernansanz-Agustin, P.; Loureiro-Lopez, M.; Guaras, A.; Casuso, R.A.; Garcia-Marques, F.; Acin-Perez, R.; Marti-Mateos, Y.; Silla-Castro, J.C.; et al. Functional role of respiratory supercomplexes in mice: SCAF1 relevance and segmentation of the Qpool. Sci. Adv. 2020, 6, eaba7509. [CrossRef]

69. Lapuente-Brun, E.; Moreno-Loshuertos, R.; Acin-Perez, R.; Latorre-Pellicer, A.; Colas, C.; Balsa, E.; Perales-Clemente, E.; Quiros, P.M.; Calvo, E.; Rodriguez-Hernandez, M.A.; et al. Supercomplex assembly determines electron flux in the mitochondrial electron transport chain. Science 2013, 340, 1567-1570. [CrossRef]

70. Aksentijevic, D.; Karlstaedt, A.; Basalay, M.V.; O’Brien, B.A.; Sanchez-Tatay, D.; Eminaga, S.; Thakker, A.; Tennant, D.A.; Fuller, W.; Eykyn, T.R.; et al. Intracellular sodium elevation reprograms cardiac metabolism. Nat. Commun. 2020, 11, 4337. [CrossRef] 
71. Luongo, T.S.; Lambert, J.P.; Gross, P.; Nwokedi, M.; Lombardi, A.A.; Shanmughapriya, S.; Carpenter, A.C.; Kolmetzky, D.; Gao, E.; Van Berlo, J.H.; et al. The mitochondrial $\mathrm{Na}(+) / \mathrm{Ca}(2+)$ exchanger is essential for $\mathrm{Ca}(2+)$ homeostasis and viability. Nature 2017, 545, 93-97. [CrossRef]

72. Hoffman, D.L.; Brookes, P.S. Oxygen sensitivity of mitochondrial reactive oxygen species generation depends on metabolic conditions. J. Biol. Chem. 2009, 284, 16236-16245. [CrossRef] [PubMed]

73. Hoffman, D.L.; Salter, J.D.; Brookes, P.S. Response of mitochondrial reactive oxygen species generation to steady-state oxygen tension: Implications for hypoxic cell signaling. Am. J. Physiol. Heart Circ. Physiol. 2007, 292, H101-H108. [CrossRef] [PubMed]

74. Jain, I.H.; Zazzeron, L.; Goldberger, O.; Marutani, E.; Wojtkiewicz, G.R.; Ast, T.; Wang, H.; Schleifer, G.; Stepanova, A.; Brepoels, K.; et al. Leigh Syndrome Mouse Model Can Be Rescued by Interventions that Normalize Brain Hyperoxia, but Not HIF Activation. Cell Metab. 2019, 30, 824-832.e823. [CrossRef] [PubMed]

75. Bianchi, C.; Genova, M.L.; Parenti Castelli, G.; Lenaz, G. The mitochondrial respiratory chain is partially organized in a supercomplex assembly: Kinetic evidence using flux control analysis. J. Biol. Chem. 2004, 279, 36562-36569. [CrossRef]

76. Acin-Perez, R.; Bayona-Bafaluy, M.P.; Fernandez-Silva, P.; Moreno-Loshuertos, R.; Perez-Martos, A.; Bruno, C.; Moraes, C.T.; Enriquez, J.A. Respiratory complex III is required to maintain complex I in mammalian mitochondria. Mol. Cell 2004, 13, 805-815. [CrossRef]

77. Balsa, E.; Soustek, M.S.; Thomas, A.; Cogliati, S.; Garcia-Poyatos, C.; Martin-Garcia, E.; Jedrychowski, M.; Gygi, S.P.; Enriquez, J.A.; Puigserver, P. ER and Nutrient Stress Promote Assembly of Respiratory Chain Supercomplexes through the PERK-eIF2alpha Axis. Mol. Cell 2019, 74, 877-890.e876. [CrossRef] [PubMed]

78. Schagger, H.; De Coo, R.; Bauer, M.F.; Hofmann, S.; Godinot, C.; Brandt, U. Significance of respirasomes for the assembly/stability of human respiratory chain complex I. J. Biol. Chem. 2004, 279, 36349-36353. [CrossRef] [PubMed]

79. Blaza, J.N.; Serreli, R.; Jones, A.J.; Mohammed, K.; Hirst, J. Kinetic evidence against partitioning of the ubiquinone pool and the catalytic relevance of respiratory-chain supercomplexes. Proc. Natl. Acad. Sci. USA 2014, 111, 15735-15740. [CrossRef]

80. Fedor, J.G.; Hirst, J. Mitochondrial Supercomplexes Do Not Enhance Catalysis by Quinone Channeling. Cell Metab. 2018, 28, 525-531.e524. [CrossRef]

81. Lobo-Jarne, T.; Nyvltova, E.; Perez-Perez, R.; Timon-Gomez, A.; Molinie, T.; Choi, A.; Mourier, A.; Fontanesi, F.; Ugalde, C.; Barrientos, A. Human COX7A2L Regulates Complex III Biogenesis and Promotes Supercomplex Organization Remodeling without Affecting Mitochondrial Bioenergetics. Cell Rep. 2018, 25, 1786-1799.e1784. [CrossRef]

82. Trouillard, M.; Meunier, B.; Rappaport, F. Questioning the functional relevance of mitochondrial supercomplexes by time-resolved analysis of the respiratory chain. Proc. Natl. Acad. Sci. USA 2011, 108, E1027-E1034. [CrossRef] [PubMed]

83. Garcia-Poyatos, C.; Cogliati, S.; Calvo, E.; Hernansanz-Agustin, P.; Lagarrigue, S.; Magni, R.; Botos, M.; Langa, X.; Amati, F.; Vazquez, J.; et al. Scaf1 promotes respiratory supercomplexes and metabolic efficiency in zebrafish. EMBO Rep. 2020, 21 , e50287. [CrossRef]

84. Letts, J.A.; Fiedorczuk, K.; Degliesposti, G.; Skehel, M.; Sazanov, L.A. Structures of Respiratory Supercomplex I+III2 Reveal Functional and Conformational Crosstalk. Mol. Cell 2019, 75, 1131-1146.e1136. [CrossRef]

85. Szibor, M.; Gainutdinov, T.; Fernandez-Vizarra, E.; Dufour, E.; Gizatullina, Z.; Debska-Vielhaber, G.; Heidler, J.; Wittig, I.; Viscomi, C.; Gellerich, F.; et al. Bioenergetic consequences from xenotopic expression of a tunicate AOX in mouse mitochondria: Switch from RET and ROS to FET. Biochim. Biophys. Acta Bioenerg. 2020, 1861, 148137. [CrossRef] [PubMed]

86. Maranzana, E.; Barbero, G.; Falasca, A.I.; Lenaz, G.; Genova, M.L. Mitochondrial respiratory supercomplex association limits production of reactive oxygen species from complex I. Antioxid. Redox Signal. 2013, 19, 1469-1480. [CrossRef] [PubMed]

87. Lopez-Fabuel, I.; Le Douce, J.; Logan, A.; James, A.M.; Bonvento, G.; Murphy, M.P.; Almeida, A.; Bolanos, J.P. Complex I assembly into supercomplexes determines differential mitochondrial ROS production in neurons and astrocytes. Proc. Natl. Acad. Sci. USA 2016, 113, 13063-13068. [CrossRef]

88. Lechuga-Vieco, A.V.; Latorre-Pellicer, A.; Johnston, I.G.; Prota, G.; Gileadi, U.; Justo-Mendez, R.; Acin-Perez, R.; Martinez-deMena, R.; Fernandez-Toro, J.M.; Jimenez-Blasco, D.; et al. Cell identity and nucleo-mitochondrial genetic context modulate OXPHOS performance and determine somatic heteroplasmy dynamics. Sci. Adv. 2020, 6, eaba5345. [CrossRef]

89. Cogliati, S.; Calvo, E.; Loureiro, M.; Guaras, A.M.; Nieto-Arellano, R.; Garcia-Poyatos, C.; Ezkurdia, I.; Mercader, N.; Vazquez, J.; Enriquez, J.A. Mechanism of super-assembly of respiratory complexes III and IV. Nature 2016, 539, 579-582. [CrossRef]

90. Moreno-Dominguez, A.; Ortega-Saenz, P.; Gao, L.; Colinas, O.; Garcia-Flores, P.; Bonilla-Henao, V.; Aragones, J.; Huttemann, M.; Grossman, L.I.; Weissmann, N.; et al. Acute O2 sensing through HIF2alpha-dependent expression of atypical cytochrome oxidase subunits in arterial chemoreceptors. Sci. Signal. 2020, 13. [CrossRef]

91. Sommer, N.; Alebrahimdehkordi, N.; Pak, O.; Knoepp, F.; Strielkov, I.; Scheibe, S.; Dufour, E.; Andjelkovic, A.; Sydykov, A.; Saraji, A.; et al. Bypassing mitochondrial complex III using alternative oxidase inhibits acute pulmonary oxygen sensing. Sci. Adv. 2020, 6, eaba0694. [CrossRef]

92. Sommer, N.; Huttemann, M.; Pak, O.; Scheibe, S.; Knoepp, F.; Sinkler, C.; Malczyk, M.; Gierhardt, M.; Esfandiary, A.; Kraut, S.; et al. Mitochondrial Complex IV Subunit 4 Isoform 2 Is Essential for Acute Pulmonary Oxygen Sensing. Circ. Res. 2017, 121, 424-438. [CrossRef] [PubMed]

93. Sommer, N.; Pak, O.; Schorner, S.; Derfuss, T.; Krug, A.; Gnaiger, E.; Ghofrani, H.A.; Schermuly, R.T.; Huckstorf, C.; Seeger, W.; et al. Mitochondrial cytochrome redox states and respiration in acute pulmonary oxygen sensing. Eur. Respir. J. 2010, 36, 1056-1066. [CrossRef] [PubMed] 
94. Weissmann, N.; Ebert, N.; Ahrens, M.; Ghofrani, H.A.; Schermuly, R.T.; Hanze, J.; Fink, L.; Rose, F.; Conzen, J.; Seeger, W.; et al. Effects of mitochondrial inhibitors and uncouplers on hypoxic vasoconstriction in rabbit lungs. Am. J. Respir. Cell Mol. Biol. 2003, 29, 721-732. [CrossRef]

95. Gupte, R.S.; Rawat, D.K.; Chettimada, S.; Cioffi, D.L.; Wolin, M.S.; Gerthoffer, W.T.; McMurtry, I.F.; Gupte, S.A. Activation of glucose-6-phosphate dehydrogenase promotes acute hypoxic pulmonary artery contraction. J. Biol. Chem. 2010, 285, 19561-19571. [CrossRef] [PubMed]

96. Xu, J.; Xu, F.; Tse, F.W.; Tse, A. ATP inhibits the hypoxia response in type I cells of rat carotid bodies. J. Neurochem. 2005, 92, 1419-1430. [CrossRef]

97. Douglas, M.G.; Cockrell, R.S. Mitochondrial cation-hydrogen ion exchange. Sodium selective transport by mitochondria and submitochondrial particles. J. Biol. Chem. 1974, 249, 5464-5471. [CrossRef]

98. Chen, Y.; McMillan-Ward, E.; Kong, J.; Israels, S.J.; Gibson, S.B. Mitochondrial electron-transport-chain inhibitors of complexes I and II induce autophagic cell death mediated by reactive oxygen species. J. Cell Sci. 2007, 120, 4155-4166. [CrossRef]

99. Kaminski, M.M.; Sauer, S.W.; Klemke, C.D.; Suss, D.; Okun, J.G.; Krammer, P.H.; Gulow, K. Mitochondrial reactive oxygen species control T cell activation by regulating IL-2 and IL-4 expression: Mechanism of ciprofloxacin-mediated immunosuppression. J. Immunol. 2010, 184, 4827-4841. [CrossRef]

100. Tschopp, J.; Schroder, K. NLRP3 inflammasome activation: The convergence of multiple signalling pathways on ROS production? Nat. Rev. Immunol. 2010, 10, 210-215. [CrossRef]

101. West, A.P.; Brodsky, I.E.; Rahner, C.; Woo, D.K.; Erdjument-Bromage, H.; Tempst, P.; Walsh, M.C.; Choi, Y.; Shadel, G.S.; Ghosh, S. TLR signalling augments macrophage bactericidal activity through mitochondrial ROS. Nature 2011, 472, 476-480. [CrossRef]

102. Zhou, R.; Yazdi, A.S.; Menu, P.; Tschopp, J. A role for mitochondria in NLRP3 inflammasome activation. Nature 2011, 469, $221-225$. [CrossRef]

103. Owusu-Ansah, E.; Banerjee, U. Reactive oxygen species prime Drosophila haematopoietic progenitors for differentiation. Nature 2009, 461, 537-541. [CrossRef] [PubMed]

104. Tormos, K.V.; Anso, E.; Hamanaka, R.B.; Eisenbart, J.; Joseph, J.; Kalyanaraman, B.; Chandel, N.S. Mitochondrial complex III ROS regulate adipocyte differentiation. Cell Metab. 2011, 14, 537-544. [CrossRef] [PubMed]

105. Weinberg, F.; Hamanaka, R.; Wheaton, W.W.; Weinberg, S.; Joseph, J.; Lopez, M.; Kalyanaraman, B.; Mutlu, G.M.; Budinger, G.R.; Chandel, N.S. Mitochondrial metabolism and ROS generation are essential for Kras-mediated tumorigenicity. Proc. Natl. Acad. Sci. USA 2010, 107, 8788-8793. [CrossRef]

106. Guzy, R.D.; Sharma, B.; Bell, E.; Chandel, N.S.; Schumacker, P.T. Loss of the SdhB, but Not the SdhA, subunit of complex II triggers reactive oxygen species-dependent hypoxia-inducible factor activation and tumorigenesis. Mol. Cell. Biol. 2008, 28, 718-731. [CrossRef] [PubMed]

107. Porporato, P.E.; Payen, V.L.; Perez-Escuredo, J.; De Saedeleer, C.J.; Danhier, P.; Copetti, T.; Dhup, S.; Tardy, M.; Vazeille, T.; Bouzin, C.; et al. A mitochondrial switch promotes tumor metastasis. Cell Rep. 2014, 8, 754-766. [CrossRef]

108. Goh, J.; Enns, L.; Fatemie, S.; Hopkins, H.; Morton, J.; Pettan-Brewer, C.; Ladiges, W. Mitochondrial targeted catalase suppresses invasive breast cancer in mice. BMC Cancer 2011, 11, 191. [CrossRef]

109. Chouchani, E.T.; Methner, C.; Nadtochiy, S.M.; Logan, A.; Pell, V.R.; Ding, S.; James, A.M.; Cocheme, H.M.; Reinhold, J.; Lilley, K.S.; et al. Cardioprotection by S-nitrosation of a cysteine switch on mitochondrial complex I. Nat. Med. 2013, 19, 753-759. [CrossRef]

110. Kohlhaas, M.; Liu, T.; Knopp, A.; Zeller, T.; Ong, M.F.; Bohm, M.; O’Rourke, B.; Maack, C. Elevated cytosolic Na+ increases mitochondrial formation of reactive oxygen species in failing cardiac myocytes. Circulation 2010, 121, 1606-1613. [CrossRef]

111. Liu, T.; Takimoto, E.; Dimaano, V.L.; DeMazumder, D.; Kettlewell, S.; Smith, G.; Sidor, A.; Abraham, T.P.; O’Rourke, B. Inhibiting mitochondrial $\mathrm{Na}+/ \mathrm{Ca} 2+$ exchange prevents sudden death in a Guinea pig model of heart failure. Circ. Res. 2014, 115, 44-54. [CrossRef] [PubMed]

112. Kostic, M.; Katoshevski, T.; Sekler, I. Allosteric Regulation of NCLX by Mitochondrial Membrane Potential Links the Metabolic State and $\mathrm{Ca}(2+)$ Signaling in Mitochondria. Cell Rep. 2018, 25, 3465-3475.e3464. [CrossRef] [PubMed]

113. Katoshevski, T.; Ben-Kasus Nissim, T.; Sekler, I. Recent studies on NCLX in health and diseases. Cell Calcium 2021, $94,102345$. [CrossRef] [PubMed]

114. Ludtmann, M.H.R.; Kostic, M.; Horne, A.; Gandhi, S.; Sekler, I.; Abramov, A.Y. LRRK2 deficiency induced mitochondrial Ca(2+) efflux inhibition can be rescued by $\mathrm{Na}(+) / \mathrm{Ca}(2+) / \mathrm{Li}(+)$ exchanger upregulation. Cell Death Dis. 2019, 10, 265. [CrossRef] [PubMed]

115. Requejo-Aguilar, R.; Lopez-Fabuel, I.; Fernandez, E.; Martins, L.M.; Almeida, A.; Bolanos, J.P. PINK1 deficiency sustains cell proliferation by reprogramming glucose metabolism through HIF1. Nat. Commun. 2014, 5, 4514. [CrossRef] [PubMed]

116. Greenamyre, J.T.; Sherer, T.B.; Betarbet, R.; Panov, A.V. Complex I and Parkinson's disease. IUBMB Life 2001, 52, 135-141. [CrossRef]

117. Stojakovic, A.; Trushin, S.; Sheu, A.; Khalili, L.; Chang, S.Y.; Li, X.; Christensen, T.; Salisbury, J.L.; Geroux, R.E.; Gateno, B.; et al. Partial inhibition of mitochondrial complex I ameliorates Alzheimer's disease pathology and cognition in APP/PS1 female mice. Commun. Biol. 2021, 4, 61. [CrossRef] 
118. Zhang, L.; Zhang, S.; Maezawa, I.; Trushin, S.; Minhas, P.; Pinto, M.; Jin, L.W.; Prasain, K.; Nguyen, T.D.; Yamazaki, Y.; et al. Modulation of mitochondrial complex I activity averts cognitive decline in multiple animal models of familial Alzheimer's Disease. EBioMedicine 2015, 2, 294-305. [CrossRef]

119. Acin-Perez, R.; Carrascoso, I.; Baixauli, F.; Roche-Molina, M.; Latorre-Pellicer, A.; Fernandez-Silva, P.; Mittelbrunn, M.; SanchezMadrid, F.; Perez-Martos, A.; Lowell, C.A.; et al. ROS-triggered phosphorylation of complex II by Fgr kinase regulates cellular adaptation to fuel use. Cell Metab. 2014, 19, 1020-1033. [CrossRef] [PubMed]

120. Garaude, J.; Acin-Perez, R.; Martinez-Cano, S.; Enamorado, M.; Ugolini, M.; Nistal-Villan, E.; Hervas-Stubbs, S.; Pelegrin, P.; Sander, L.E.; Enriquez, J.A.; et al. Mitochondrial respiratory-chain adaptations in macrophages contribute to antibacterial host defense. Nat. Immunol. 2016, 17, 1037-1045. [CrossRef]

121. Bleier, L.; Wittig, I.; Heide, H.; Steger, M.; Brandt, U.; Drose, S. Generator-specific targets of mitochondrial reactive oxygen species. Free Radic. Biol. Med. 2015, 78, 1-10. [CrossRef] [PubMed] 